\title{
Nutrition, Fats, Monosaturated
}

National Cancer Institute

\section{Source}

National Cancer Institute. Nutrition, Fats, Monosaturated. NCI Thesaurus. Code C16106.

Study of monosaturated fats in relation to cancer. 